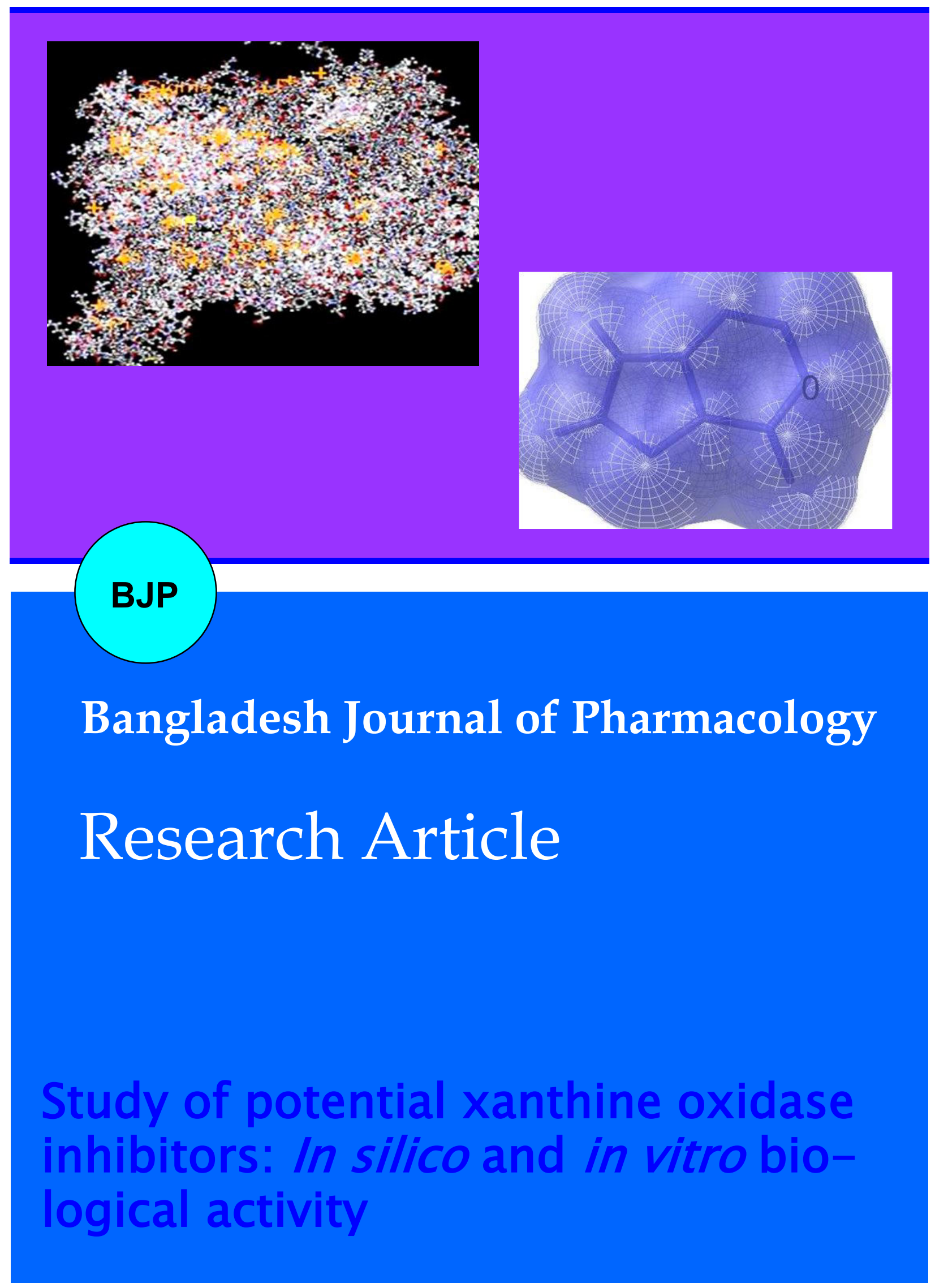




\section{Study of potential xanthine oxidase inhibitors: In silico and in vitro biological activity}

\section{Muthuswamy Umamaheswari, Arumugam Madeswaran, Kuppusamy Asokkumar, Thirumalaisamy Sivashanmugam, Varadharajan Subhadradevi and Puliyath Jagannath}

Department of Pharmacology, College of Pharmacy, Sri Ramakrishna Institute of Paramedical Sciences, Coimbatore, Tamil Nadu, India.

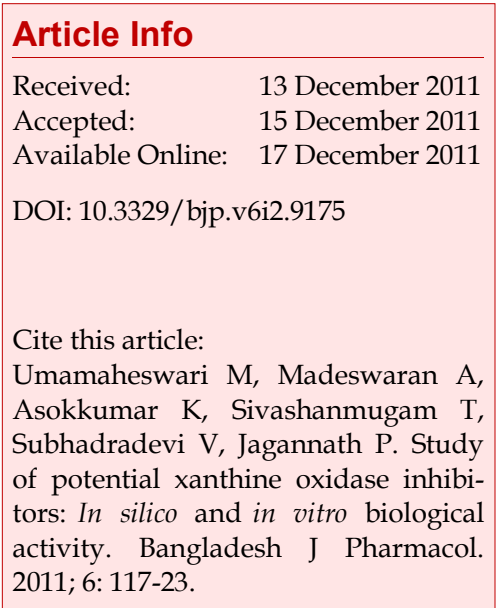

\begin{abstract}
In an attempt to develop potent anti gout agents, coumarin derivatives and polyphenolic compounds were selected for present study. The docking energy of 2-benzyl coumarin was found to be $-7.5 \mathrm{kcal} / \mathrm{mol}$ which was less than that of the standard allopurinol $(-4.5 \mathrm{kcal} / \mathrm{mol})$. All the selected compounds were found to exhibit lower binding energy $(-7.5$ to $-4.7 \mathrm{kcal} /$ mol) than allopurinol. Docking results confirm that selected compounds showed greater inhibition of xanthine oxidase due to their active binding sites. In xanthine oxidase assay, $\mathrm{IC}_{50}$ value of 2-benzyl coumarin was found to be $26 \pm 1.2 \mu \mathrm{g} / \mathrm{mL}$, whereas that of allopurinol was $24 \pm 0.3 \mu \mathrm{g} / \mathrm{mL}$. All the compounds exhibited $\mathrm{IC}_{50}$ values ranging between $26 \pm 1.2$ to $58 \pm 0.7 \mu \mathrm{g} / \mathrm{mL}$. In enzyme kinetic studies, coumarin derivatives showed competitive and polyphenolic compounds showed non competitive type of enzyme inhibition. It can be concluded that coumarin derivatives could be a remedy for the treatment of gout and related inflammatory disorders.
\end{abstract}

\section{Introduction}

Drug design is an important tool in the field of medicinal chemistry where the new compounds are synthesized by molecular or chemical manipulation of the lead moiety in order to produce a highly active compound with minimum steric effect (Cavasotto and Abagyan, 2004). Search for new ligands and the assessment, improvement and extension of the lead is a very important step in identification of new chemical entitie (Borges et al., 2002). The main objective of drug design is to improve efficacy, potency and to minimize or eliminate untoward side effects.

Virtual screening analysis can help in identifying drug targets via bioinformatics tools. They are used to analyze the target structures for possible binding sites, generation of candidate molecules, checking for their drug likeness, docking the molecules with the target, rank them according to their binding affinities, and further optimization of the molecules to improve binding characteristics (Breda et al., 2008). AutoDock 4.2 is a suite of automated docking tools. It usually starts with the definition of a binding site, in general a restricted region of the protein. AutoDock uses Monte Carlo and Simulated Annealing in combination with Genetic Algorithm which is used for global optimization (Morris et al., 1998).

Xanthine oxidase $(\mathrm{XO})$ is a highly versatile enzyme that is widely distributed among different species from bacteria to man and within the various tissues of mammals. It is a member of group of enzymes known as molybdenum iron-sulfur flavin hydroxylases (Symons et al., 1989). The hydroxylation of purines is catalysed by the enzyme xanthine oxidase and especially the conversion of xanthine to uric acid (Niu et al., 2011). It is one of the major enzymes involved in 
the catabolism of purine nucleotides. It converts hypoxanthine and xanthine to uric acid. There is substantial evidence that over activity of this enzyme leads to a condition, generally called gout (Pacher et al., 2006). Gout is characterized by an excessive concentration of uric acid in the blood, causing the accumulation of monosodium urate crystals in the joints and kidneys leading to acute goutry arthritis, tophi of the joints and extremities and uric acid nephrolithiasis (Umamaheswari and Chatterjee, 2008). Elevated levels of uric acid not only leads to gout but also results in the development of hypertension, cardiovascular diseases, diabetes, obesity, cancer and hyperlipidemia (Hediger, 2005).

Xanthine oxidase inhibitors (XOI) are much useful, since they possess lesser side effects compared to uricosuric and anti inflammatory agents. Allopurinol is the only clinically available XOI, which also suffers from many side effects such as hypersensitivity syndrome, Steven's Johnson syndrome and renal toxicity (Umamaheswari et al., 2009). Thus, there is necessary to develop compounds with XOI activity with lesser side effects when compared to allopurinol.

The stereochemistry of coumarin and poly phenolic derivatives binding on xanthine oxidase has not been characterized. We thus began our work with the in silico docking studies and in vitro xanthine oxidase inhibitory activity of some commercially available coumarin and polyphenolic compounds.

\section{Materials and Methods}

\section{Software required}

Python 2.7-language was downloaded from www.python.com, Cygwin (a data storage) c: \program and Python 2.5 were simultaneously downloaded from www.cygwin.com, Molecular graphics laboratory (MGL) tools and AutoDock4.2 was downloaded from www.scripps.edu, Discovery studio visualizer 2.5.5 was downloaded from www.accelerys.com, Molecular orbital package (MOPAC), Chemsketch was downloaded from www.acdlabs.com. Online smiles translatory notation was carried out using cactus.nci.nih.gov/ translate.

\section{Docking analysis}

We employed the Lamarckian genetic algorithm (LGA) for ligand conformational searching, which is a hybrid of a genetic algorithm and a local search algorithm. This algorithm first builds a population of individuals (genes), each being a different random conformation of the docked molecule. Each individual is then mutated to acquire a slightly different translation and rotation and the local search algorithm then performs energy minimizations on a user-specified proportion of the

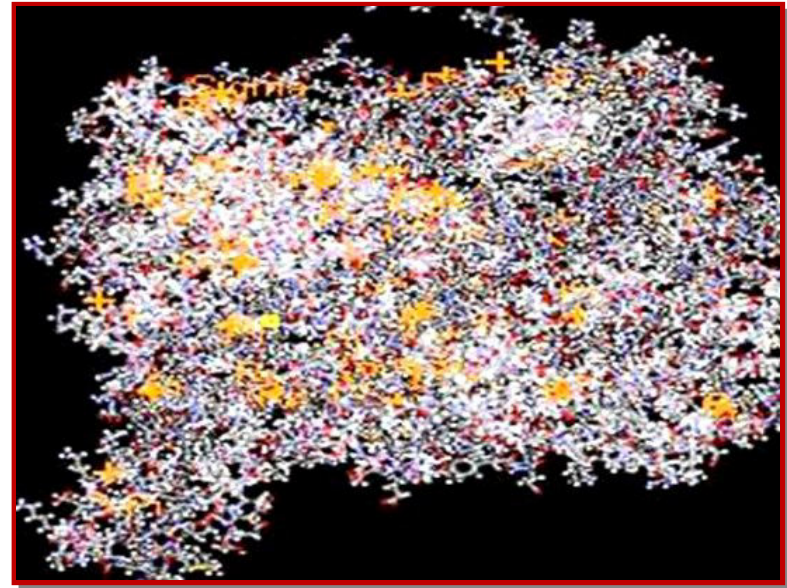

Figure 1: Xanthine oxidase from bovine milk source (3BDJ)

population of individuals. The individuals with the low resulting energy are transferred to the next generation and the process is then repeated. The algorithm is called Lamarckian because every new generation of individuals is allowed to inherit the local search adaptations of their parents.

\section{Coordinate file preparation}

An extended PDB format, termed as PDBQT file was used for coordinate files which includes atomic partial charges. AutoDock Tools was used for creating PDBQT files from traditional PDB files (Khodade et al., 2007). Crystal structure of xanthine oxidase enzyme from bovine milk source was downloaded from the RCSB protein data bank (Figure 1).

The coumarin derivatives like 7-hydroxycoumarin, Bis hydroxy coumarin, 2-benzylcoumarin, 7-hydroxy-4methyl coumarin and the polyphenolic derivatives like ferulic acid, gallic acid, phloroglucinol, 1,4-naphthoquinone, 1,2-naphthoquinone and the standard allopurinol were built using ChemSketch and optimized using "Prepare Ligands" in the AutoDock 4.2 for docking studies (Figure 2). The optimized ligand molecules were docked into refined xanthine oxidase model using "LigandFit" in the AutoDock 4.2 (Goodsell et al., 1996; Umamaheswari et al., 2011).

\section{AutoGrid calculation}

Rapid energy evaluation was achieved by precalculating atomic affinity potentials for each atom in the ligand molecule. In the AutoGrid procedure, the target enzyme was embedded on a three dimensional grid point (Umamaheswari et al., 2012). The energy of interaction of each atom in the ligand was encountered.

The preparation of the target protein 3BDJ (unbound target) with the AutoDock Tools software involved adding all hydrogen atoms to the macromolecule, which is a step necessary for correct calculation of partial atomic charges. Gasteiger charges are calculated 


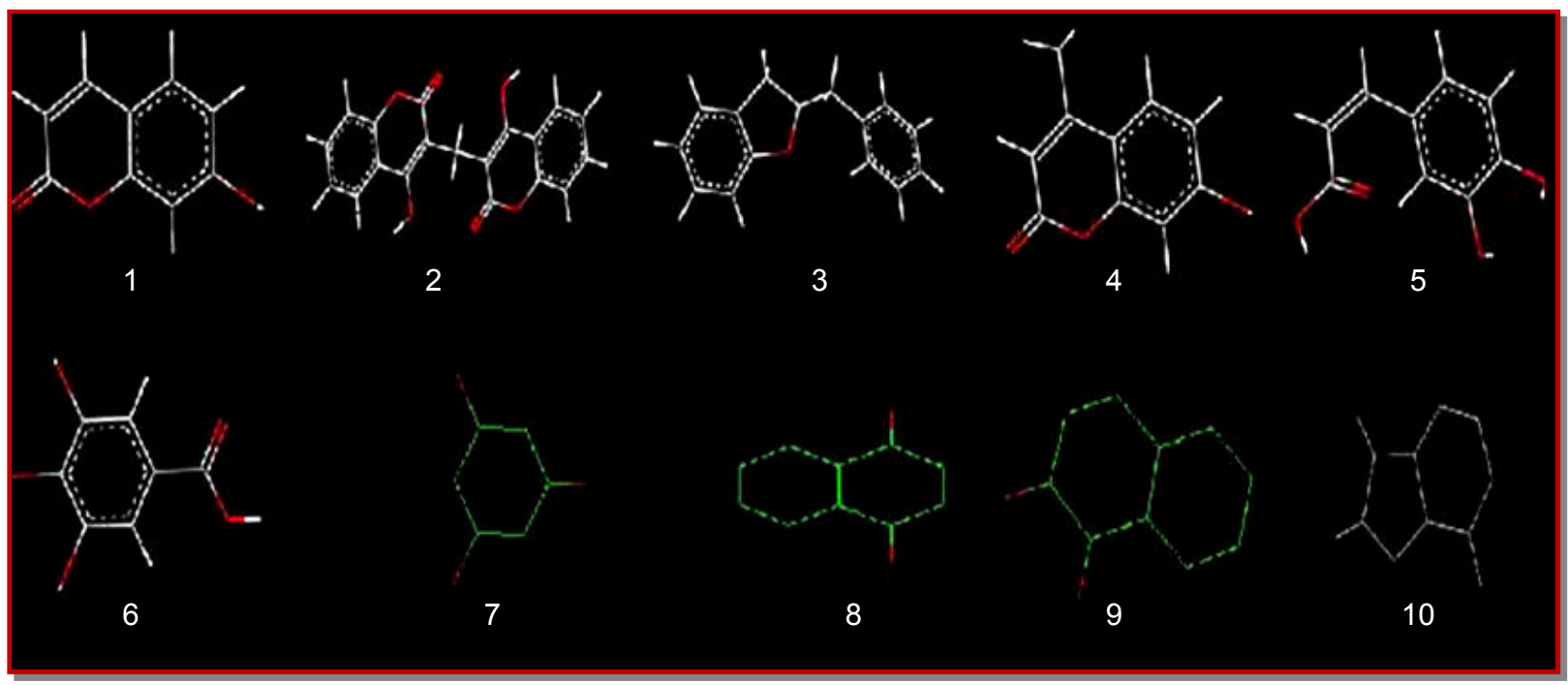

Figure 2: The optimized ligand molecules (1) 7-hydroxy coumarin, (2) bishydroxy coumarin, (3) 2-benzyl coumarin, (4) 7hydroxy-4- methyl coumarin, (5) ferulic acid, (6) gallic acid, (7) phloroglucinol, (8) 1,4-naphthoquinone, (9) 1,2naphthoquinone, (10) allopurinol)

for each atom of the macromolecule in AutoDock 4.2 instead of Kollman charges which were used in the previous versions of this program. Three-dimensional affinity grids of size $277 \times 277 \times 277 \AA$ with $0.6 \AA$ spacing were centered on the geometric center of the target protein and were calculated for each of the following atom types: HD, C, A, N, OA, and SA, representing all possible atom types in a protein. Additionally, an electrostatic map and a desolvation map were calculated (Konc et al., 2011).

Rapid energy evaluation was achieved by precalculating atomic affinity potentials for each atom in the ligand molecule. In the AutoGrid procedure, the target enzyme was embedded on a three dimensional grid point. The energy of interaction of each atom in the ligand was encountered.

\section{AutoDock calculation}

Docking can be carried out by various methods. But, the most efficient method is Lamarckian genetic algorithm. AutoDock was run several times to get various docked conformations, and used to analyze the predicted docking energy. The binding sites for these molecules were selected based on the ligand-binding pocket of the templates (Chang et al., 2010).

We set important docking parameters for the LGA as follows: Population size of 150 individuals, 2.5 million energy evaluations, maximum of 27,000 generations, number of top individuals to automatically survive to next generation of 1 , mutation rate of 0.02 , crossover rate of $0.8,150$ docking runs, and random initial positions and conformations. The probability of performing local search on an individual in the population was set to 0.06 and the maximum number of iterations per local search was set to 300. Unbound target 3D3L and unbound ligands were both treated as rigid (Park et al., 2006).

\section{Analysis using AutoDock tools}

AutoDock tools provide various methods to analyze the results of docking simulations such as, conformational similarity, visualizing the binding site and its energy and other parameters like intermolecular energy and inhibition constant. For each ligand, ten best poses were generated and scored using AutoDock 4.2 scoring functions (Umamaheswari et al., 2011).

\section{In vitro xanthine oxidase inhibitory activity}

The assay mixture consisted of $1 \mathrm{~mL}$ of the test compound (5-100 $\mu \mathrm{g} / \mathrm{mL}), 2.9 \mathrm{~mL}$ of phosphate buffer (pH 7.5) and $0.1 \mathrm{~mL}$ of xanthine oxidase enzyme solution (0.1 units/mL in phosphate buffer, $\mathrm{pH} 7.5)$, which was prepared immediately before use. After preincubation at $25^{\circ} \mathrm{C}$ for $15 \mathrm{~min}$ the reaction was initiated by the addition of various concentrations of the substrate solution $(2 \mathrm{~mL})$. The assay mixture was incubated at $25^{\circ} \mathrm{C}$ for $30 \mathrm{~min}$. The reaction was stopped by adding $1 \mathrm{~mL}$ of $1 \mathrm{~N} \mathrm{HCl}$ and the absorbance was measured at $290 \mathrm{~nm}$ using UV spectrophotometer. Allopurinol $(5-100 \mu \mathrm{g} / \mathrm{mL})$ was used as the standard. The percentage inhibition was calculated by,

\section{Percentage inhibition $=[(A-B)-(C-D)] /(A-B) \times 100$}

Where, A is the activity of the enzyme without the compound, B is the control of A without the compound and enzyme, C and D are the activities of the compound with and without the enzyme respectively. The assay was done in triplicate and $\mathrm{IC}_{50}$ values were calculated from the percentage inhibition (Werns et al., 1991). 


\section{Enzyme kinetics studies}

Lineweaver-Burk plot analysis was performed to determine the mode of inhibition of the most active coumarin derivatives and polyphenolic compounds and compared with allopurinol. The assay was carried out in presence or absence of the compounds with varying concentrations of xanthine as the substrate, employing xanthine oxidase assay as mentioned earlier. The Lineweaver-Burk transformed values were plotted to determine the mode of enzyme inhibition (Kimura et al., 2010).

\section{Results and Discussion}

The docking poses were ranked according to their docking scores and both the ranked list of docked ligands and their corresponding binding poses (Zhang et al., 2008). In Figure 3, docked pose of xanthine oxidase enzyme with silbinin and galangin ligands clearly demonstrated the binding positions of the ligand with the enzyme.

Binding energy of the individual compound were calculated using the following formula,

Binding energy $=\mathrm{A}+\mathrm{B}+\mathrm{C}-\mathrm{D}$

Where, A denotes final intermolecular energy + Wander valls energy $(\mathrm{vdW})+$ hydrogen bonds +

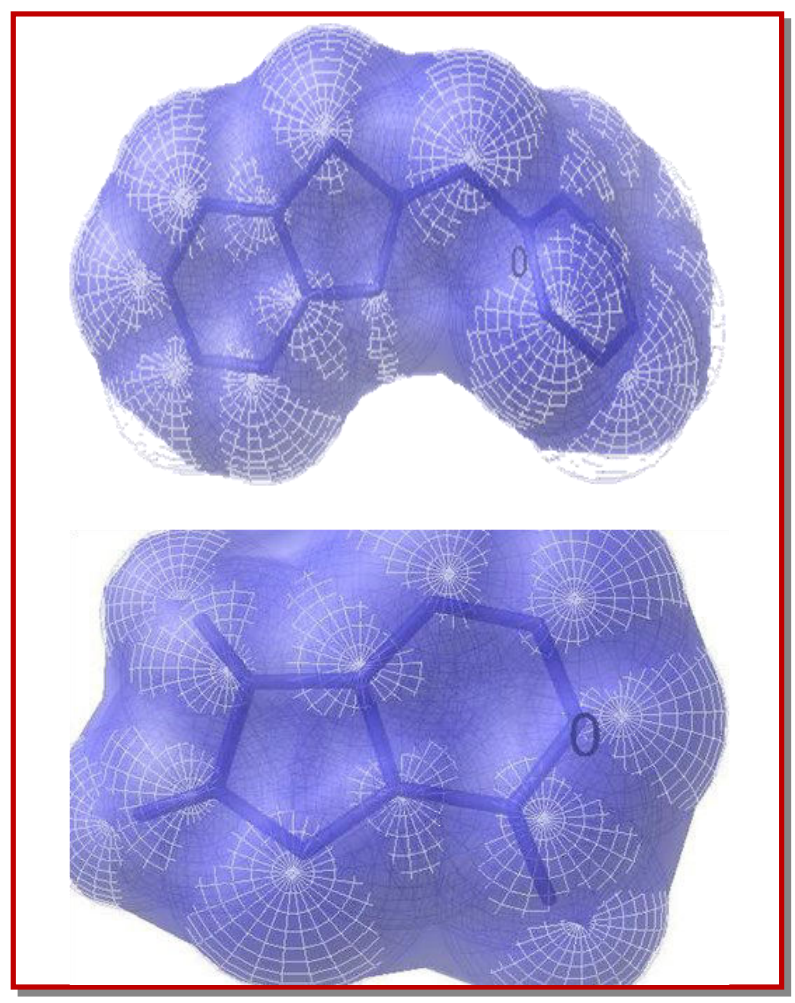

Figure 3: Docked pose of xanthine oxidase enzyme (3BDJ) with 2 benzylcoumarin and allopurinol desolvation energy + electrostatic energy $(\mathrm{kcal} / \mathrm{mol}), \mathrm{B}$ denotes final total internal energy $(\mathrm{kcal} / \mathrm{mol}), \mathrm{C}$ denotes torsional free energy $(\mathrm{kcal} / \mathrm{mol}), \mathrm{D}$ denotes unbound system's energy $(\mathrm{kcal} / \mathrm{mol})$.

Analysis of the receptor/ligand complex models generated after successful docking of the coumarin derivatives and polyphenolic compounds was based on the parameters such as, hydrogen bond interactions, $\Pi-$ $\Pi$ interactions, binding energy, RMSD of active site residues and orientation of the docked compound within the active site (Azam et al., 2011). As a general rule, in most of the potent antigout compounds, both hydrogen bond and $\Pi-\Pi$ hydrophobic interactions between the compound and the active sites of the receptor have been found to be responsible for mediating the biological activity.

Coumarin derivatives and polyphenolic compounds showed binding energy ranging between -7.5 to -4.7 $\mathrm{kcal} / \mathrm{mol}$ (Table I). All the selected coumarin derivatives and polyphenolic compounds had lesser binding energy when compared to the standard allopurinol $(-4.5 \mathrm{kcal} / \mathrm{mol})$. This proves that coumarin derivatives and polyphenolic compounds consist of potential xanthine oxidase inhibitory binding sites when compared to the standard.

In addition, two other parameters like inhibition constant $\left(\mathrm{K}_{\mathrm{i}}\right)$ and intermolecular energy were also determined. Coumarin derivatives and polyphenolic compounds showed inhibition constant ranging from 3.2 to $368.1 \mu \mathrm{M}$ (Table II). All the selected compounds had lesser inhibition constant when compared to the standard $(529.7 \mu \mathrm{M})$.

Inhibition constant is directly proportional to binding energy. We found a decrease in inhibition constant of all the selected coumarin derivatives and polyphenolic compounds with a simultaneous decrease in the binding energy. Thus, the xanthine oxidase inhibitory activity of the coumarin derivatives and polyphenolic compounds were found to be higher compared to allopurinol.

As shown in Table III, coumarin derivatives and polyphenolic compounds showed intermolecular energy ranging between -8.1 to -5.6 which was lesser when compared to the standard (-4.5). Intermolecular energy is also directly proportional to binding energy. We found a decrease in intermolecular energy of all the selected compounds with a simultaneous decrease in the binding energy. This result further proved the xanthine oxidase inhibitory activity of all the selected coumarin derivatives and polyphenolic compounds.

Based on the docking studies, the xanthine oxidase inhibitory activity of the selected compounds was found to be decreased in the order of 2-benzyl coumarin, 7-hydroxy-4-methyl coumarin, bis hydroxy 


\section{Table I}

\section{Binding energies of the compounds based on their rank}

\begin{tabular}{|c|c|c|c|c|c|c|c|c|c|c|}
\hline \multirow[t]{2}{*}{ Compound } & \multicolumn{10}{|c|}{ Binding energies of the compounds based on their rank (kcal/mol) } \\
\hline & 1 & 2 & 3 & 4 & 5 & 6 & 7 & 8 & 9 & 10 \\
\hline 7-Hydroxy coumarin & -6.1 & -6.0 & -5.9 & -6.0 & -6.0 & -6.0 & -5.9 & -5.4 & -5.4 & -4.9 \\
\hline Bishydroxy coumarin & -6.4 & -6.3 & -4.9 & -6.1 & -5.8 & -5.5 & -5.9 & -5.9 & -5.9 & -5.4 \\
\hline 2-Benzyl coumarin & -7.5 & -7.5 & -7.5 & -7.5 & -7.3 & -7.3 & -7.3 & -7.2 & -7.2 & -6.9 \\
\hline $\begin{array}{l}\text { 7-Hydroxy-4-methyl } \\
\text { coumarin }\end{array}$ & -6.5 & -6.5 & -6.4 & -6.4 & -6.4 & -6.3 & -5.8 & -5.8 & -5.7 & -5.6 \\
\hline Ferulic acid & -5.9 & -5.7 & -5.6 & -5.4 & -5.3 & -4.9 & -4.2 & -4.0 & -3.6 & -3.2 \\
\hline Gallic acid & -5.5 & -4.8 & -5.3 & -5.3 & -4.7 & -4.6 & -4.3 & -4.1 & -4.4 & -3.6 \\
\hline Phloroglucinol & -4.7 & -4.6 & -4.5 & -4.2 & -4.2 & -4.2 & -4.2 & -4.2 & -4.1 & -4.1 \\
\hline 1,4-Naphthoquinone & -6.0 & -6.0 & -6.0 & -6.0 & -6.0 & -6.0 & -5.8 & -5.7 & -5.7 & -5.6 \\
\hline 1,2-Naphthoquinone & -6.1 & -6.1 & -6.1 & -6.1 & -6.1 & -6.1 & -6.1 & -6.1 & -5.4 & -4.6 \\
\hline Allopurinol & -4.5 & -4.5 & -4.5 & -4.5 & -4.5 & -4.2 & -4.1 & -4.1 & -4.0 & -3.9 \\
\hline
\end{tabular}

Table II

Inhibition constant of the compounds based on their rank

\begin{tabular}{|c|c|c|c|c|c|c|c|c|c|c|}
\hline \multirow{2}{*}{ Compound } & \multicolumn{10}{|c|}{ Inhibition constant of the compounds based on their rank $(\mu \mathrm{M}, \mathrm{mMa})$} \\
\hline & 1 & 2 & 3 & 4 & 5 & 6 & 7 & 8 & 9 & 10 \\
\hline 7-Hydroxy coumarin & 34.5 & 38.3 & 44.5 & 40.5 & 40.5 & 40.8 & 48.5 & 109.8 & 116.7 & 242.3 \\
\hline Bishydroxy coumarin & 19.3 & 26.1 & 262.7 & 35.0 & 59.3 & 86.5 & 48.3 & 48.4 & 51.6 & 120.3 \\
\hline 2-Benzyl coumarin & 3.2 & 3.3 & 3.4 & 3.4 & 4.5 & 4.6 & 4.6 & 5.0 & 5.0 & 9.5 \\
\hline $\begin{array}{l}\text { 7-Hydroxy-4-methyl } \\
\text { coumarin }\end{array}$ & 18.3 & 18.8 & 19.0 & 20.9 & 21.3 & 23.0 & 57.4 & 57.8 & 61.7 & 85.8 \\
\hline Ferulic acid & 47.3 & 69.5 & 83.1 & 109.2 & 142.6 & 242.2 & 796.2 & $1.1^{\mathrm{a}}$ & $2.1^{\mathrm{a}}$ & $4.7^{\mathrm{a}}$ \\
\hline Gallic acid & 94.4 & 282.7 & 132.1 & 142.3 & 384.2 & 397.1 & 742.9 & $1.1^{\mathrm{a}}$ & 617.0 & $2.5^{\mathrm{a}}$ \\
\hline Phloroglucinol & 368.1 & 429.1 & 537.8 & 729.3 & 831.7 & 808.0 & 810.1 & 853.0 & 937.9 & $1.1^{\mathrm{a}}$ \\
\hline 1,4-Naphthoquinone & 39.8 & 40.0 & 40.1 & 40.5 & 41.0 & 41.1 & 59.2 & 63.8 & 63.6 & 80.0 \\
\hline 1,2-Naphthoquinone & 31.3 & 31.6 & 32.4 & 32.5 & 32.6 & 32.7 & 33.1 & 33.7 & 107.2 & 397.0 \\
\hline Allopurinol & 529.7 & 534.1 & 541.0 & 541.3 & 545.6 & 830.9 & $1.0^{\mathrm{a}}$ & $1.0^{\mathrm{a}}$ & $1.2^{\mathrm{a}}$ & $1.5^{\mathrm{a}}$ \\
\hline
\end{tabular}

coumarin, 7-hydroxy coumarin, 1,2-naphthoquinone, 1,4-naphthoquinone, ferulic acid, gallic acid, phloroglucinol and allopurinol. On the basis of the above study, coumarin derivatives like 2-benzyl coumarin, 7hydroxy-4-methyl coumarin, bis hydroxy coumarin, 7hydroxy coumarin possess the highest xanthine oxidase inhibitory sites when compared to that of the polyphenolic compounds and standard. This may due to the difference in the position of functional groups in the compounds.

An increase in xanthine oxidase activity leads to an increase in the uric acid level, causing renal stone formation, ischemic myocardial infarction and free radical mediated diseases (Unno et al., 2004). Recent findings suggest that the occurrence of gout is increasing worldwide, possibly due to intake of foods rich in nucleic acid, such as organ meats and some types of sea food. Hypouricemic agents like xanthine oxidase inhibitors and uricosuric agents are commonly employed in the treatment of chronic gouty arthritis (Pacher et al., 2002).

A dose-dependent xanthine oxidase inhibitory activity was observed for all the selected compounds. Inhibition of xanthine oxidase resulted in a decreased production of uric acid, when measured spectroscopically. Among the coumarin derivatives, 2-benzyl coumarin was found to possess highest activity ( $\mathrm{IC}_{50} 26 \pm 1.2 \mu \mathrm{g} / \mathrm{mL}$ ) while, considering the polyphenolic compounds, ferulic acid showed lesser $\mathrm{IC}_{50}$ value $(36 \pm 0.6 \mu \mathrm{g} / \mathrm{mL})$. The activity of 2-benzyl coumarin was found to be greater than the standard, allopurinol $(29 \pm 0.3 \mu \mathrm{g} / \mathrm{mL})$. All the compounds demonstrated XOI activity at a concentration below $100 \mu \mathrm{g} / \mathrm{mL}$, with $\mathrm{IC}_{50}$ values ranging from 26 to $58 \mu \mathrm{g} / \mathrm{mL}$. The XOI activity of the compounds were in 


\section{Table III}

Intermolecular energies of the compounds based on their rank

\begin{tabular}{|c|c|c|c|c|c|c|c|c|c|c|}
\hline \multirow{2}{*}{ Compound } & \multicolumn{10}{|c|}{ Intermolecular energies of the compounds based on their rank } \\
\hline & 1 & 2 & 3 & 4 & 5 & 6 & 7 & 8 & 9 & 10 \\
\hline 7- Hydroxy coumarin & -6.4 & -6.3 & -6.2 & -6.3 & -6.3 & -6.3 & -6.2 & -5.7 & -5.7 & -5.2 \\
\hline Bis hydroxy coumarin & -7.6 & -7.5 & -6.1 & -7.3 & -7.0 & -6.7 & -7.1 & -7.1 & -7.0 & -6.5 \\
\hline 2- Benzyl coumarin & -8.1 & -8.1 & -8.1 & -8.1 & -7.9 & -7.9 & -7.9 & -7.8 & -7.8 & -7.5 \\
\hline $\begin{array}{l}\text { 7- Hydroxy -4- methyl } \\
\text { coumarin }\end{array}$ & -6.8 & -6.8 & -6.7 & -6.7 & -6.7 & -6.6 & -6.1 & -6.1 & -6.0 & -5.9 \\
\hline Ferulic acid & -7.4 & -7.2 & -7.1 & -6.9 & -6.7 & -6.4 & -5.7 & -5.5 & -5.1 & -4.7 \\
\hline Gallic acid & -7.0 & -6.3 & -6.8 & -6.7 & -6.2 & -6.1 & -5.8 & -5.5 & -5.9 & -5.0 \\
\hline Phloroglucinol & -5.6 & -5.5 & -5.4 & -5.1 & -5.1 & -5.1 & -5.1 & -5.1 & -5.0 & -4.9 \\
\hline 1,4 - Naphthoquinone & -6.0 & -6.0 & -6.0 & -6.0 & -6.0 & -6.0 & -5.8 & -5.7 & -5.7 & -5.6 \\
\hline 1,2 - Naphthoquinone & -6.1 & -6.1 & -6.1 & -6.1 & -6.1 & -6.1 & -6.1 & -6.1 & -5.4 & -4.6 \\
\hline Allopurinol & -4.5 & -4.5 & -4.5 & -4.5 & -4.5 & -4.2 & -4.1 & -4.1 & -4.0 & -3.9 \\
\hline
\end{tabular}

Table IV

In vitro xanthine oxidase inhibitory activity of the selected compounds

\begin{tabular}{|c|c|c|c|c|c|c|}
\hline \multirow[t]{3}{*}{ Compound } & \multicolumn{5}{|c|}{ Percentage inhibition } & \multirow{3}{*}{$\begin{array}{c}\mathrm{IC}_{50}(\mu \mathrm{g} / \\
\mathrm{mL})\end{array}$} \\
\hline & \multicolumn{5}{|c|}{ Concentration $(\mu \mathrm{g} / \mathrm{mL})$} & \\
\hline & 5 & 20 & 40 & 60 & 80 & \\
\hline 7-Hydroxy coumarin & $34.0 \pm 0.8$ & $45.0 \pm 0.8$ & $52.7 \pm 0.4$ & $58.3 \pm 0.7$ & $64.7 \pm 1.3$ & $35.0 \pm 0.9$ \\
\hline Bis hydroxy coumarin & $26.3 \pm 0.8$ & $40.6 \pm 0.8$ & $64.4 \pm 0.5$ & $72.0 \pm 0.8$ & $78.7 \pm 0.6$ & $29.0 \pm 0.4$ \\
\hline 2-Benzyl coumarin & $32.0 \pm 0.8$ & $39.3 \pm 0.9$ & $54.3 \pm 0.6$ & $76.0 \pm 0.8$ & $85.3 \pm 1.3$ & $26.0 \pm 1.2$ \\
\hline 7-Hydroxy-4-methyl coumarin & $22.3 \pm 0.8$ & $42.6 \pm 1.0$ & $62.7 \pm 0.7$ & $68.5 \pm 0.7$ & $76.4 \pm 1.0$ & $28.0 \pm 0.6$ \\
\hline Ferulic acid & $31.2 \pm 0.7$ & $44.5 \pm 0.9$ & $54.3 \pm 0.6$ & $74.5 \pm 1.2$ & $87.5 \pm 0.9$ & $36.0 \pm 0.6$ \\
\hline Gallic acid & $16.0 \pm 1.0$ & $32.7 \pm 1.3$ & $39.7 \pm 1.1$ & $57.7 \pm 0.5$ & $66.0 \pm 0.6$ & $47.0 \pm 0.6$ \\
\hline Phloroglucinol & $18.0 \pm 1.2$ & $30.7 \pm 0.8$ & $36.0 \pm 1.3$ & $51.3 \pm 0.6$ & $61.7 \pm 0.5$ & $58.0 \pm 0.7$ \\
\hline 1,4-Naphthoquinone & $18.0 \pm 0.5$ & $29.3 \pm 0.8$ & $41.3 \pm 0.3$ & $56.0 \pm 0.6$ & $61.3 \pm 0.8$ & $52.0 \pm 0.3$ \\
\hline 1,2-Naphthoquinone & $16.0 \pm 0.6$ & $32.7 \pm 0.8$ & $39.3 \pm 1.4$ & $54.3 \pm 1.2$ & $62.0 \pm 0.6$ & $54.0 \pm 0.6$ \\
\hline Allopurinol & $33.3 \pm 0.7$ & $38.0 \pm 0.9$ & $66.0 \pm 1.2$ & $76.7 \pm 1.4$ & $97.3 \pm 0.9$ & $29.0 \pm 0.3$ \\
\hline
\end{tabular}

the order of 2-benzyl coumarin >7-hydroxy-4-methyl coumarin $>$ bishydroxy coumarin, allopurinol $>7$-hydroxycoumarin $>$ ferulic acid $>$ gallic acid $>1$,4-naphthoquinone $>1,2$-naphthoquinone $>$ phloroglucinol.

The in vitro results were in corroboration with the in silico studies as evidenced by a decrease in binding energy, intermolecular energy and inhibition constant.

The enzyme kinetic studies were carried out using Lineweaver Burk plot analysis. All the coumarin derivatives and standard allopurinol were found to exhibit competitive mode of xanthine oxidase inhibition and the polyphenolic compounds showed non competitive inhibition.

\section{Conclusion}

This study clearly indicate that coumarin derivatives have excellent binding interactions with xanthine oxidase than the polyphenolic compounds. Further investigations on the above compounds and in vivo studies are necessary to develop potential chemical entities for the prevention and treatment of gout and related inflammatory disorders.

\section{References}

Azam F, Prasad MVV, Thangavel N. Molecular docking studies of 1-(substituted phenyl)-3-(naphtha [1,2-d] thiazol - 
2-yl) urea/thiourea derivatives with human adenosine A2A receptor. Bioinformation 2011; 6: 330-34.

Borges F, Feranandes E, Roleira F. Progress towards the discovery of xanthine oxidase inhibitors. Curr Med Chem. 2002; 9: 195-217.

Breda A, Basso LA, Santos DS, de Azevedo Jr WF. Virtual screening of drugs: Score functions, docking, and drug design. Curr Computer-Aided Drug Design. 2008; 4: 265-72.

Cavasotto $\mathrm{CN}$, Abagyan RA. Protein flexibility in ligand docking and virtual screening to protein kinases. J Mol Biol. 2004; 12: 209-25.

Chang MW, Ayeni C, Breuer S. Virtual screening for HIV protease inhibitors: A comparison of AutoDock 4 and vina. PLoS ONE. 2010; 5: 119-55.

Goodsell DS, Morris GM, Olson AJ. Automated docking of flexible ligands: Applications of Autodock. J Mol Recog. 1996; 9: 1-5.

Hediger AM. Molecular physiology of urate transport. Physiol. 2005; 20: 125-33.

Khodade P, Prabhu R, Chandra N. Parallel implementation of AutoDock. J App Crystal. 2007; 40: 598-99.

Kimura Y, Ito H, Ohnishi R, Hatano T. Inhibitory effects of polyphenols on human cytochrome P450 3A4 and 2C9 activity. Food Chem Toxicol. 2010; 48: 429-35.

Konc J, Konc JT, Penca M, Janezic M. Binding-sites prediction assisting protein-protein docking. Acta Chim Slov. 2011; 58: 396-401.

Morris G, Goodsell D, Halliday R. Automated docking using Lamarckian genetic algorithm and an empirical binding free energy function. J Comp Chem. 1998; 19: 1639-62.

Niu Y, Zhu H, Liu J, Fan H, Sun L, Lu W, Liu X, Li L. 3,5,2',4'Tetrahydroxychalcone, a new non-purine xanthine oxidase inhibitor. Chem Biol Inter. 2011; 189: 161-66.

Pacher P, Mabley GJ, Soriano GF, Liaudet L, Komjati K, Szabo C. Endothelial dysfunction in aging animals: The role of poly (ADP-ribose) polymerase activation. Br J Pharmacol. 2002;

\section{5: $1347-50$.}

Pacher P, Nivorozhkin A, Szabo C. Therapeutic effect of xanthine oxidase inhibitors: Renaissance half a century after the discovery of allopurinol. Pharmacol Rev. 2006; 58: 87114.

Park H, Lee J, Lee S. Critical assessment of the automated AutoDock as a new docking tool for virtual screening. Proteins 2006; 65: 549-54.

Symons CRM, Taiwo AF, Petersen LR. Electron addition to xanthine oxidase. An electron spins resonance study of the effects of ionizing radiation. J Chem Soci. 1989; 85: 4063-74.

Umamaheswari M, Asokkumar K, Sivashanmugam AT, Remyaraju A, Subhadradevi V, Ravi TK. In vitro xanthine oxidase inhibitory activity of the fractions of Erythrina stricta Roxb. J Ethnopharmacol. 2009; 124: 646-48.

Umamaheswari M, Chatterjee TK. Hypouricemic and xanthine oxidase inhibitory activities of the fractions of Coccinia grandis L.Voigt. OPEM. 2008; 7: 477-84.

Umamaheswari M, Madeswaran A, Asokkumar K, Sivashanmugam AT, Subhadradevi V, Jagannath V. Docking studies: Search for possible phytoconstituents for the treatment of gout. Int J Biol Pharm Res. 2012; 3: 6-11.

Umamaheswari M, Madeswaran A, Asokkumar K, Sivashanmugam $T$, Subhadradevi V, Jagannath P. Discovery of potential xanthine oxidase inhibitors using in silico docking studies. Der Pharma Chemica. 2011; 3: 240-47.

Unno T, Sugimoto A, Kakuda T. Xanthine oxidase inhibitors from the leaves of Lagerstroemia species (L.) Pers J Ethnopharmacol. 2004; 93: 391-95.

Werns SW, Grum CM, Ventura A, Hahn RA, Ho PP, Towner RD, Fantone JC, Schork MA, Lucchesi BR. Xanthine oxidase inhibition does not limit canine infarct size. Circulation 1991; 83: 995-1005.

Zhang S, Kumar K, Jiang X. DOVIS: An implementation for high throughput virtual ening using AutoDock. BMC Bioinformatics. 2008; 9: 126-28.
Author Info
Muthuswamy Umamaheswari (Principal contact)
e-mail: umasaravanaprakash@gmail.com 